\title{
The free-living flatworm Macrostomum lignano
}

\author{
Jakub Wudarski ${ }^{1}$, Bernhard Egger ${ }^{2}$, Steven A. Ramm³ ${ }^{3}$ Lukas Schärer ${ }^{4}$, Peter Ladurner ${ }^{2}$, Kira S. Zadesenets $^{5}$, \\ Nikolay B. Rubtsov ${ }^{5}$, Stijn Mouton ${ }^{1}$ and Eugene Berezikov ${ }^{1,5^{*}}$ (i)
}

\begin{abstract}
Macrostomum lignano is a free-living flatworm that is emerging as an attractive experimental animal for research on a broad range of biological questions. One feature setting it apart from other flatworms is the successful establishment of transgenesis methods, facilitated by a steady supply of eggs in the form of single-cell zygotes that can be readily manipulated. This, in combination with the transparency of the animal and its small size, creates practical advantages for imaging and fluorescence-activated cell sorting in studies related to stem cell biology and regeneration. M. lignano can regenerate most of its body parts, including the germline, thanks to the neoblasts, which represent the flatworm stem cell system. Interestingly, neoblasts seem to have a high capacity of cellular maintenance, as M. lignano can survive up to $210 \mathrm{~Gy}$ of $\gamma$-irradiation, and partially offset the negative consequence of ageing. As a non-self-fertilizing simultaneous hermaphrodite that reproduces in a sexual manner, $M$. lignano is also used to study sexual selection and other evolutionary aspects of sexual reproduction. Work over the past several years has led to the development of molecular resources and tools, including high-quality genome and transcriptome assemblies, transcriptional profiling of the germline and somatic neoblasts, gene knockdown, and in situ hybridization. The increasingly detailed characterization of this animal has also resulted in novel research questions, such as bio-adhesion based on its adhesionrelease glands and genome evolution due to its recent whole-genome duplication.
\end{abstract}

Keywords: Macrostomum, Flatworms, Regeneration, Neoblasts, Transgenesis, Ageing, Re-diploidization, Sex allocation, Sexual selection, Bio-adhesion

\section{Natural habitat and life cycle}

The flatworm Macrostomum lignano is a free-living, marine species belonging to the Macrostomorpha, the earliest branching clade of Rhabditophora [1] (Fig. 1). The species is found on the beaches of the Northern Adriatic and the Aegean Sea. It is adapted to live in the interstitial spaces between sand grains in the upper intertidal zone, a zone not covered by water during every tidal cycle (Fig. 2a). As a result, the animals are exposed to variable environmental conditions and can cope with a

\footnotetext{
*Correspondence: e.berezikov@umcg.nl

${ }^{1}$ European Research Institute for the Biology of Ageing, University

of Groningen, University Medical Center Groningen, Antonius Deusinglaan 1,9713AV Groningen, The Netherlands

Full list of author information is available at the end of the article
}

broad range of temperatures, salinities, and oxygen concentrations [2-4]. Adult animals are 1-2 $\mathrm{mm}$ in length and $0.3 \mathrm{~mm}$ in width (Fig. 2b). The epidermis is multiciliated and animals move by coordinated ciliary beating. Beneath the epidermis and a thin basal matrix lies the body wall musculature consisting of circular, diagonal, and longitudinal fibers, which permit the animal to perform body movements (Additional file 1). Major organ systems include a central nervous system with a brain anterior to the paired eyes, a mouth, a pharynx and a blind-ending rod-shaped gut, paired testes anterior to paired ovaries, female and male genital openings, and a sclerotised copulatory organ in the tail plate [5]. M. lignano is an obligately non-self-fertilizing species that reproduces exclusively in a sexual manner [6] (Additional

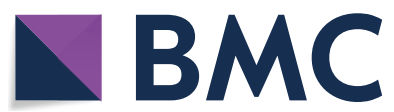

(c) The Author(s) 2020. This article is licensed under a Creative Commons Attribution 4.0 International License, which permits use, sharing, adaptation, distribution and reproduction in any medium or format, as long as you give appropriate credit to the original author(s) and the source, provide a link to the Creative Commons licence, and indicate if changes were made. The images or other third party material in this article are included in the article's Creative Commons licence, unless indicated otherwise in a credit line to the material. If material is not included in the article's Creative Commons licence and your intended use is not permitted by statutory regulation or exceeds the permitted use, you will need to obtain permission directly from the copyright holder. To view a copy of this licence, visit http://creativeco mmons.org/licenses/by/4.0/. The Creative Commons Public Domain Dedication waiver (http://creativecommons.org/publicdomain/ zero/1.0/) applies to the data made available in this article, unless otherwise stated in a credit line to the data. 

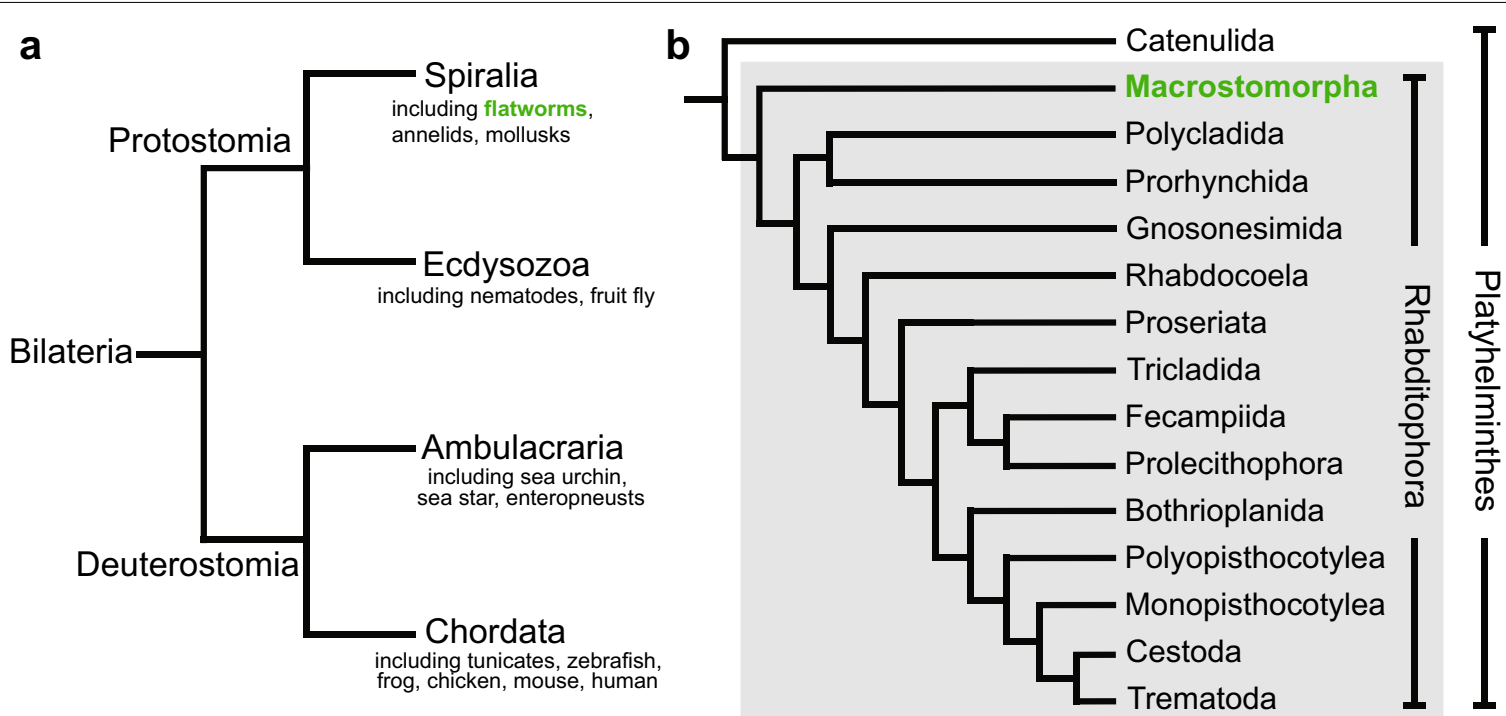

Fig. 1 Phylogenetic position of Macrostomum lignano. a Overview of the systematic position of flatworms in the animal tree of life. $\mathbf{b}$ Interrelationships of the flatworm orders, modified after [46]. M. lignano is a member of the Macrostomorpha (green)
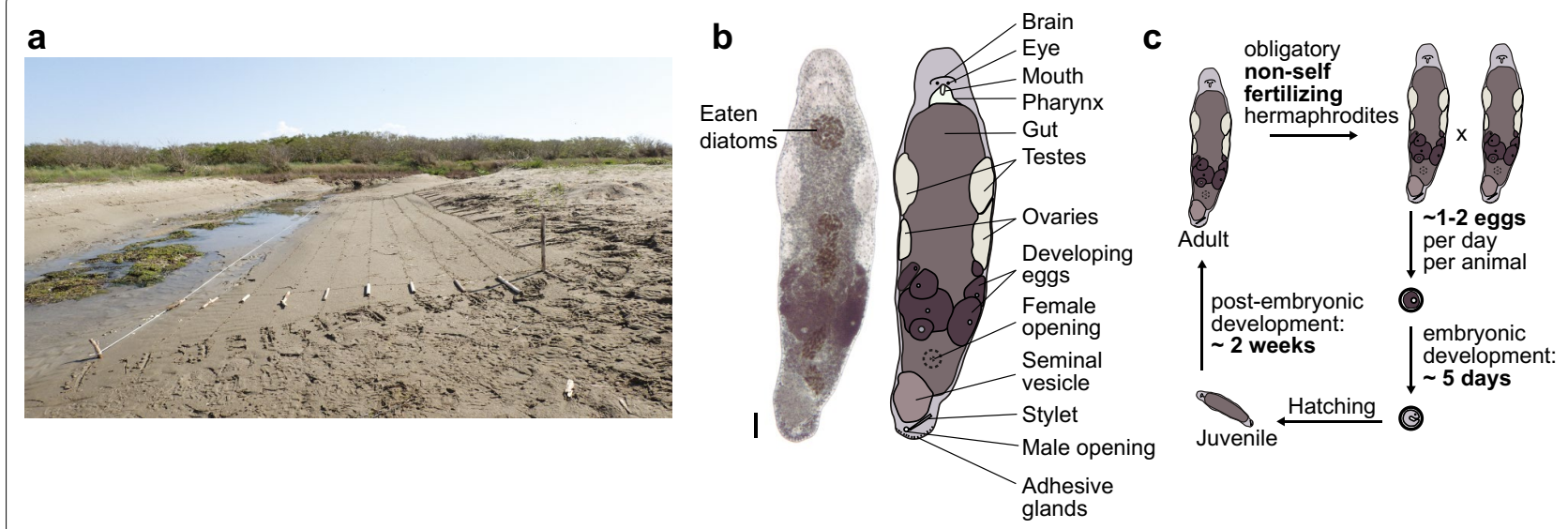

Fig. 2 Macrostomum lignano habitat, morphology, and life cycle. a The natural habitat of $M$. lignano in the upper intertidal zone of the Northern Adriatic. A systematic transect to study the distribution of Macrostomum species at Bocca d'Anfora, Italy, is shown. b Bright-field image and schematic representation of an adult worm (lightly squeezed to allow for better observation). Scale bar $100 \mu \mathrm{m}$. c Schematic visualization of the M. lignano life cycle

file 2). Worms lay single-cell fertilized eggs (zygotes), and embryonic development takes 5 days (Additional file 3), after which a juvenile emerges through a pre-determined hatch in the egg shell and directly develops into a mature animal in less than 2 weeks (Fig. 2c) [7].

\section{Field collection and laboratory culture}

Macrostomum lignano can be readily extracted from field-collected sand samples using a classical meiofauna extraction technique, i.e., decantation after $\mathrm{MgCl}_{2}$ anaesthesia. Often, samples contain many meiofaunal species, including multiple species of Macrostomum. Species identification, therefore, requires detailed observation of a lightly squeezed worm in a so-called squeeze preparation under a compound microscope. The main distinguishing feature of $M$. lignano compared to other Macrostomum species is the shape and size of the male copulatory stylet [5].

Macrostomum lignano is a lab-friendly organism. Worms can be kept in Petri dishes with artificial sea water as the medium and unicellular diatom algae of the species Nitzschia curvilineata as food source. Starvation 
causes animals to decrease in size, regress the reproductive system, and reduce mitotic activity of the neoblasts. Feeding such animals will, in turn, induce an increase of neoblast proliferation, growth, and re-establishment of the germline [8]. The optimal laboratory conditions are $20{ }^{\circ} \mathrm{C}$ and a $14 \mathrm{~h} / 10 \mathrm{~h}$ day/night cycle. However, the worms can survive in a temperature range between $4{ }^{\circ} \mathrm{C}$ and $37{ }^{\circ} \mathrm{C}$ [2], making it easy to maintain the culture even without specialized equipment. M. lignano exhibits negative phototaxis, which helps concentrating the animals at a desired spot in a Petri dish (Additional file 4). An adult animal produces 1-2 eggs per day, and a group of 20 worms can produce over 200 progeny in 1 week, providing ample access to research material. In addition, there are various worm lines available including many inbred (e.g., DV1, NL12) and transgenic (e.g., HUB1 with nearly ubiquitous expression of GFP, NL24 with mScarlet expression in ovaries and $\mathrm{mNeonGreen} \mathrm{in} \mathrm{testes)} \mathrm{lines} \mathrm{[9,}$ 10].

\section{Major interests and research questions Stem cells and regeneration}

Macrostomum lignano has a large population of stem cells, called neoblasts, which are located in two lateral bands in the parenchyma, in close proximity to the main lateral nerve cords, and merge in the tail plate [11]. The rostrum, the region anterior of the eyes, is devoid of neoblasts (Fig. 3). Neoblasts are defined by their ability to divide-they are the only proliferating somatic cells in the animal and thus the only source of new cells [11-14]. The neoblast population drives a high cellular turnover during adult tissue homeostasis and provides the regeneration capacity [12]. As in planarians, the neoblast pool of $M$. lignano is assumed to be heterogeneous, including pluripotent and lineage-restricted stem cells. This is supported by indications that a small fraction of the neoblast population is slow cycling or quiescent $[13,15]$. Transcriptional profiling of somatic neoblasts and germline cells was recently performed [16]. However, direct evidence for neoblast heterogeneity and pluripotency in $M$. lignano is still lacking, and identifying different types of neoblasts and characterizing the molecular regulation of differentiation into both somatic and germline lineages are a major open research question.

Macrostomum lignano can regenerate missing body parts anterior to the brain and posterior to the pharynx (Fig. 3). The regeneration process can be easily observed (Additional file 5), and includes stages of wound closure, formation of a blastema, and the subsequent restoration of the missing tissues and organs [17]. How this complex process is regulated remains poorly understood, and we envision that the experimental power of M. lignano will help to unravel the molecular mechanisms behind all

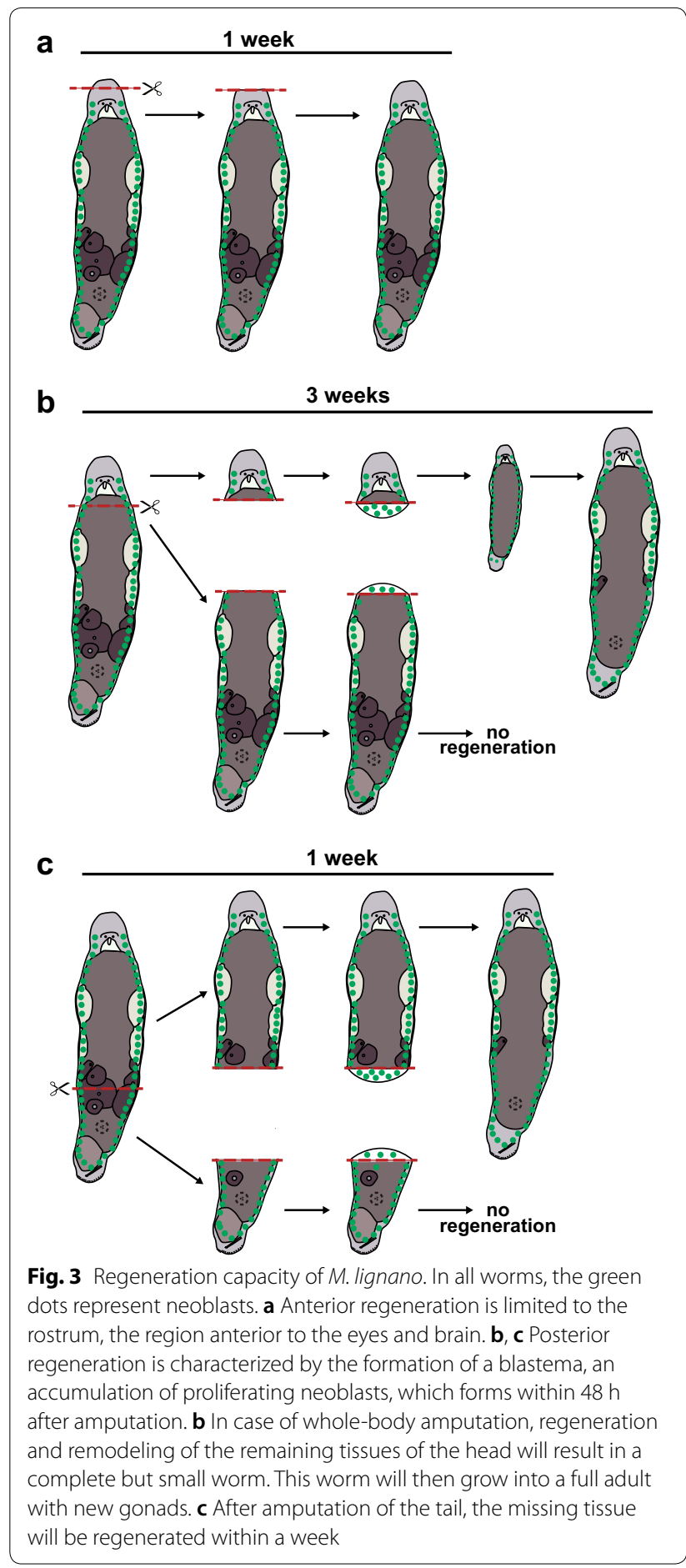

stages of regeneration, including initiation, proliferation, and patterning.

\section{Ageing and resistance to DNA damage}

The regeneration capacity is maintained with advancing age, and worms have a lifespan of more than 2 years $[18$, 
19], which is remarkable for an animal of this small size. In contrast to asexual planarians, $M$. lignano does, however, demonstrate phenotypic signs of ageing, such as the appearance of cysts and loss of eyes [18, 19]. Analysis of RNA-sequencing data of ageing animals revealed a significant age-dependent upregulation of neoblast transcripts and several pro-longevity genes, suggesting that $M$. lignano evolved molecular mechanisms to maintain stem cell function and, at least partially, offset the negative consequences of ageing [18]. Dissecting the ageing resilience mechanisms in $M$. lignano may provide significant novel insights for ageing research. One such mechanism is probably connected to genome maintenance, since the worms are highly resistant to external sources of DNA damage, such as ionizing radiation. Full elimination of neoblasts in $M$. lignano requires a fractionated total dose of 210 Gy of $\gamma$-irradiation, compared to just a few Gy in mammals [20]. At doses below $210 \mathrm{~Gy}$, the stem cell system can recover and animals survive [16, 20]. Thus, investigation of molecular mechanisms of DNA protection and repair in $M$. lignano holds great promise.

\section{Genome re-diploidization}

The M. lignano haploid genome size is $502 \mathrm{Mb}$, [9] and its karyotype $(2 n=8)$ consists of a pair of large and three pairs of small metacentric chromosomes (Fig. 4a) $[21,22]$. Interestingly, in some laboratory lines, including the DV1 line used for the initial genome sequencing $[9,23]$, chromosome polymorphisms were revealed, associated mostly with copy-number variation of the large chromosome $[9,22]$, resulting in an increase of the genome size to $742 \mathrm{Mb}$ [9]. Fluorescence in situ hybridization (FISH) analyses suggest that the largest chromosome is derived from a fusion of all small chromosomes, followed by deletions and inversions of some chromosome regions (Fig. 4b), indicating that the modern genome of $M$. lignano may have formed through a recent whole-genome duplication event followed by re-diploidization, including fusion of one full haploid chromosome set into one large metacentric chromosome [24, 25]. This peculiarity of $M$. lignano makes it attractive for studies of early stages of genome and chromosome evolution after whole-genome duplication in animals.

\section{Embryonic development}

Macrostomum lignano undergoes a modified spiralcleavage pattern (Additional file 3), which deviates after the eight-cell stage when yolk-rich and opaque hull cells of embryonic origin start surrounding the inner blastomeres, impeding live observations $[7,26]$. This challenge can be overcome with advanced microscopy, such as 4D microscopy [26] and light sheet microscopy [27], or with histological sections $[7,26]$. In contrast to other spiralians, the mesentoblast (forming major parts of mesoand endoderm) is not a descendant of blastomere $4 \mathrm{~d}$ in M. lignano [21]. The unusual blastomeric origin of the meso- and endoderm compared to other flatworms (polyclads and prorhynchids) is, therefore, a major research question.

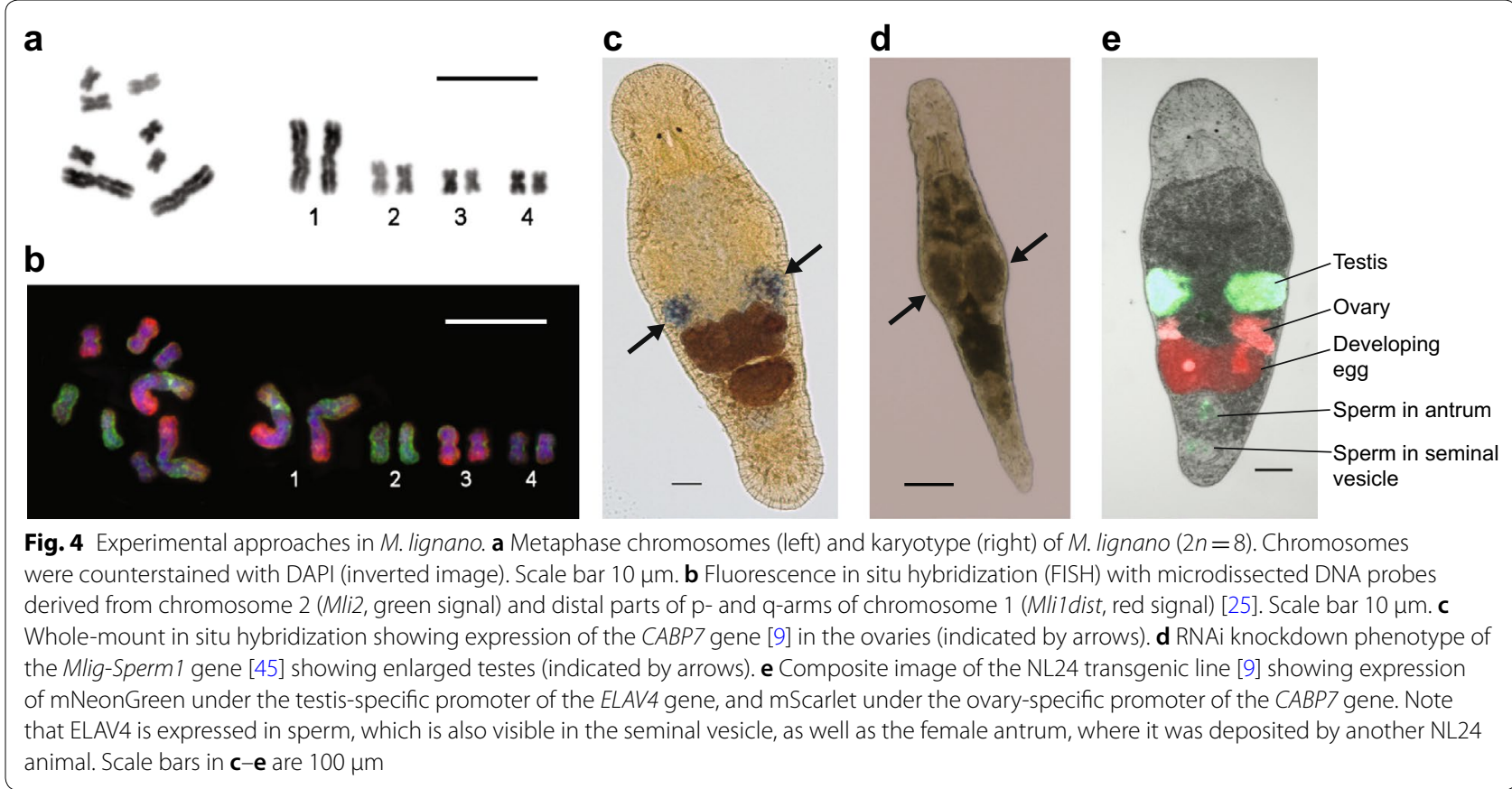




\section{Evolution of sexual reproduction}

Macrostomum lignano has long been used as a model system for understanding evolutionary aspects of sex allocation, sexual selection, and sexual conflict in simultaneous hermaphrodites. This is aided by the transparency of the worm permitting in vivo observations of internal structures and processes, including the non-invasive measurement of gonad size and the tracking of GFP-expressing sperm $[28,29]$. The species provides some of the strongest empirical support for sex allocation theory pertaining to how individuals should optimally partition investment between their male and female sex functions $[6,28,30$, 31]. Moreover, the genus Macrostomum exhibits diversity in reproductive traits, including in behaviour and morphology, making it well suited also for comparative studies of reproductive trait evolution [32]. A major research question now is to better understand how Macrostomum species with contrasting and divergent reproductive behaviours and morphologies differ with respect to the mechanisms of sexual selection and sexual conflict.

\section{Bio-adhesion}

Macrostomum lignano can attach to any natural substrate, followed by controlled detachment [33, 34]. This reversible attachment relies on a duo-gland adhesionrelease system which consists of $\sim 130$ adhesive organs located on the ventral side of the tail plate [33, 35]. Each adhesive organ is comprised of three cell types: an adhesive gland cell, a releasing gland cell, and a modified epidermal cell called the anchor cell. Recent studies revealed a number of adhesion-related transcripts and two large proteins that mediate temporary adhesion of $M$. lignano $[34,36]$. Using proteomic data, antibody, and lectin staining, as well as interference of attachment using specific molecules and surfaces, a model for M. lignano attachment and release was proposed [34]. Overall, a better understanding of $M$. lignano bio-adhesion could lead to the generation of synthetic equivalents for medical and industrial applications.

\section{Experimental approaches}

\section{Immunohistochemistry and in situ hybridization}

The small, transparent body and detailed morphological understanding facilitate the use of light and fluorescent imaging in whole animals. Antibody labeling is commonly used to label proliferating neoblasts by means of BrdU incorporation and a polyclonal antibody against phosphorylated Histone H3 [11]. Polyclonal antibodies against, e.g., Vasa [33], Piwi [37], and Boule [38], were produced. In addition, monoclonal antibodies against various cell types, tissues and organs (e.g., spermatids, ventral nerve cord, prostate glands, gut, muscles, and epidermis) were developed [39]. Patterns of gene expression can be visualized in whole animals by in situ hybridization (Fig. 4c) [40].

\section{RNAi}

RNA interference (RNAi) is performed by simply soaking animals in double-stranded RNA (dsRNA) dissolved in culture medium (Fig. 4d). While this technique is easy, it is labor-intensive and has a rather low throughput. The dsRNA fragments can be made in the laboratory with an in vitro transcription protocol [41].

\section{Transgenesis}

The key feature making M. lignano stands out among other flatworm model organisms is the availability of transgenic techniques. The worms lay large, single-cell, fertilized eggs that can be microinjected using standard micromanipulation equipment. An established microinjection protocol, coupled with high-quality genome and transcriptome assemblies and the short generation time of the animal, enables the creation of stable transgenic lines in a matter of a few weeks. Several lines with tissuespecific and heatshock-inducible expression are already available (Fig. 4e, Additional file 6) [2, 9]. The published transgenesis approach relies on random integration of injected DNA constructs into the genome and does not require specialized vectors. Stable transgenic lines can be obtained from $1-8 \%$ of the injected eggs [9], and around 30-50 eggs can typically be injected in a single session. The use of other transgenesis methods, such as transposon-mediated integration, homologous recombination, and the CRISPR/Cas9 system for genome editing, should be feasible in M. lignano, but remain to be developed.

\section{Live imaging}

The transparency of $M$. lignano is especially advantageous for live imaging (Additional file 7). Worms can be immobilized using $\mathrm{MgCl}_{2}$ as an anaesthetic and squeeze preparations. The small thickness of the body makes it easy to observe changes in worm morphology even under low magnification stereoscopes and is very helpful for confocal imaging.

\section{Flow cytometry and FACS}

Worms can be macerated into a single-cell suspension using Otto buffers [12] or Accutase. Subsequent flow cytometry and FACS can be performed using standard techniques.

\section{Karyotyping}

A single-worm karyotyping technique allows monitoring of karyotypes in laboratory cultures of worms (Fig. 4a) [22]. The detailed chromosome organization can be investigated by FISH using different types of DNA 
probes, including microdissected region- and chromosome-specific DNA probes (Fig. 4b) [24, 25]. Since $M$. lignano shows chromosomal polymorphisms [9, 22], it is important to regularly monitor laboratory cultures for the spontaneous duplication of the large chromosome, which can be performed using flow cytometry [9]. Although the chromosomal polymorphisms potentially complicate the use of $M$. lignano as a model for genetic studies, in practice, we have not experienced such problems when using an inbred line NL12, which is derived from wild-type line NL10 [9] and shows a stable karyotype $(2 n=8)$.

\section{Behaviour}

The small size of the worms, in combination with digital time-lapse video recording, permits very efficient observation of mating interactions of many individuals simultaneously (Additional file 8), facilitating detailed and well-replicated behavioural studies [29, 42-44]. Since it is easy to generate a lot of behavioural observations, it would be interesting to take advantage of recent developments in image analysis and machine learning, to convert such observations into quantitative data in an automated and time-efficient way.

\section{Research community and resources Macrostomum meeting, ISFB}

The Macrostomum research community currently comprises about ten laboratories worldwide. Macrostomum researchers are meeting approximately yearly since 2007 in the format of the 2-day International Macrostomum Meeting (IMM), which all researchers interested in initiating research on Macrostomum are highly welcome to join. Moreover, many members of the Macrostomum research community also regularly attend the International Symposium on Flatworm Biology (ISFB), which usually takes place every 3 years and brings together researchers that work on free-living flatworms, parasitic flatworms, and acoels.

\section{The Macrostomorpha Taxonomy and Phylogeny website}

A good reference for field collection, observation, and documentation of Macrostomum is the Methods section of the Macrostomorpha Taxonomy and Phylogeny website (http://macrostomorpha.info). This website contains digital versions of most of the taxonomic publications in the genus Macrostomum and its parent taxon Macrostomorpha, and serves as a repository for information about taxonomic-type specimens and images of reference specimens (digital hologenophore vouchers) that have been used in molecular phylogenetic analyses in this group of flatworms [32].

\section{Genome, transcriptome, genome browser}

The most recent annotated $M$. lignano genome assembly version Mlig_3_7_DV1 [9] is available at GenBank (acc. no. NIVC00000000.1) and on the Macrostomum genome resources website (http://www.macgenome. org). The genome can be explored using the UCSC genome browser interface at http://gb.macgenome.org.

\section{Nanotomy}

A whole-animal electron microscopy atlas obtained at the nanoscale provides a "Google-Earth" style of data presentation and navigation at different levels of resolution [45], and is accessible at http://www.nanotomy. org/OA/Macrostomum.

\section{Neoblast and ageing data interfaces}

There are two web interfaces, http://neoblast.macge nome.org and http://ageing.macgenome.org, which provide a straightforward way to search, visualize, and analyse gene expression data generated in the recent $M$. lignano neoblast/germline and ageing studies $[16,18]$.

\section{Supplementary information}

Supplementary information accompanies this paper at https://doi. org/10.1186/s13227-020-00150-1.

Additional file 1. Movie of adult M. lignano animals eating diatom algae. Additional file 2. Movie of mating worms. Two individuals of $M$. lignano are engaged in a reciprocal mating, which is followed by one individual performing the post-copulatory suck behavior (from 22-27 s), after which some sperm can be seen sticking out of the vagina of the worm (final frames). Video from https://www.flickr.com/photos/lukas_scharer/15281 560757 under a CC-BY 2.0 licence.

Additional file 3. Movie of the early stages of embryonic development in M. lignano.

Additional file 4. Movie demonstrating negative phototaxis behaviour in M. lignano.

Additional file 5. Movie of an amputated M. lignano head. It will regenerate into a full animal within 3 weeks.

Additional file 6. Movie of the transgenic M. lignano line NL24, where testes are marked by expression of mNeonGreen under the ELAV4 promoter and ovaries by expression of mScarlet under the CABP7 promoter.

Additional file 7. Movie showing live imaging of the $M$. lignano tail region. The high level of transparency of these worms permits detailed observations of anatomical structures in living worms, namely, in order of appearance in the video, the adhesive glands (dotted arc), the male genital opening (small ciliated circle), the large drop-shaped and spermfilled false seminal vesicle (on the right), the smaller and muscular true seminal vesicle, the vesicula granulorum (with prostate gland granules), the copulatory stylet (long tube from left to right), and some rotating food particles inside of the lumen of the gut.

Additional file 8. Observations on the mating interactions in many pairs of M. lignano. A $12 \mathrm{~s}$ clip of a longer time-lapse video (captured at 1 frame per second and played back at 10 frames per second) showing the interactions in a total of 18 pairs, each placed into individual $4 \mu \mathrm{l}$ drops 
in an observation chamber. Within many of the pairs one can observe precopulatory, copulatory, and postcopulatory interactions.

\section{Authors' contributions}

All authors contributed to writing and revising the manuscript. All authors read and approved the final manuscript.

\section{Funding}

This work is supported by the Russian Foundation for Basic Research (RFBR, Grant No. 18-04-01011 to EB), the Russian Science Foundation (RSF, Grant No. 19-14-00211 to KZ and NB), the Swiss National Science Foundation (SNSF, Grant No. 310030_184916 to LS), the Austrian Science Fund (FWF, Grant No. P30347 to PL), and a grant for young scientists from the University of Innsbruck (to BE).

\section{Availability of data and materials}

Not applicable.

\section{Ethics approval and consent to participate}

Not applicable.

\section{Consent for publication}

Not applicable.

\section{Competing interests}

The authors declare that they have no competing interests.

\section{Author details}

'European Research Institute for the Biology of Ageing, University of Groningen, University Medical Center Groningen, Antonius Deusinglaan 1, 9713AV Groningen, The Netherlands. ${ }^{2}$ Institute of Zoology and Center for Molecular Biosciences Innsbruck, University of Innsbruck, Technikerstr. 25, 6020 Innsbruck, Austria. ${ }^{3}$ Department of Evolutionary Biology, Bielefeld University, Morgenbreede 45, 33615 Bielefeld, Germany. ${ }^{4}$ Department of Environmental Sciences, Zoological Institute, University of Basel, Vesalgasse 1, 4051 Basel, Switzerland. ${ }^{5}$ The Federal Research Center Institute of Cytology and Genetics SB RAS, Prospekt Lavrentyeva 10, Novosibirsk 630090, Russia.

Received: 16 November 2019 Accepted: 12 February 2020

Published online: 02 March 2020

\section{References}

1. Egger B, Lapraz F, Tomiczek B, Müller S, Dessimoz C, Girstmair J, et al. A transcriptomic-phylogenomic analysis of the evolutionary relationships of flatworms. Curr Biol. 2015;25(10):1347-53.

2. Wudarski J, Ustyantsev K, Glazenburg L, Berezikov E. Influence of temperature on development, reproduction and regeneration in the flatworm model organism. Macrostomum lignano. Zool Lett. 2019;5:7.

3. Rivera-Ingraham GA, Nommick A, Blondeau-Bidet E, Ladurner P, Lignot $J \mathrm{H}$. Salinity stress from the perspective of the energy-redox axis: lessons from a marine intertidal flatworm. Redox Biol. 2016;10:53-64.

4. Rivera-Ingraham GA, Bickmeyer U, Abele D. The physiological response of the marine platyhelminth Macrostomum lignano to different environmental oxygen concentrations. J Exp Biol. 2013;216(14):2741-51.

5. Ladurner P, Schärer L, Salvenmoser W, Rieger RM. A new model organism among the lower Bilateria and the use of digital microscopy in taxonomy of meiobenthic Platyhelminthes: Macrostomum lignano, n. sp. (Rhabditophora, Macrostomorpha). J Zool Syst Evol Res. 2005;43(2):114-26.

6. Schärer $L$, Ladurner P. Phenotypically plastic adjustment of sex allocation in a simultaneous hermaphrodite. Proc R Soc B Biol Sci. 2003;270(1518):935-41.

7. Morris J, Nallur R, Ladurner P, Egger B, Rieger R, Hartenstein V. The embryonic development of the flatworm Macrostomum sp. Dev Genes Evol. 2004;214(5):220-39

8. Nimeth KT, Mahlknecht M, Mezzanato A, Peter R, Rieger R, Ladurner P. Stem cell dynamics during growth, feeding, and starvation in the basal flatworm Macrostomum sp. (Platyhelminthes). Dev Dyn. 2004;230(1):91-9.
9. Wudarski J, Simanov D, Ustyantsev K, de Mulder K, Grelling M, Grudniewska $M$, et al. Efficient transgenesis and annotated genome sequence of the regenerative flatworm model Macrostomum lignano. Nat Commun. 2017;8(1):2120.

10. Vellnow N, Vizoso DB, Viktorin G, Schärer L. No evidence for strong cytonuclear conflict over sex allocation in a simultaneously hermaphroditic flatworm. BMC Evol Biol. 2017;17(1):103.

11. Ladurner P, Rieger R, Baguñà J. Spatial distribution and differentiation potential of stem cells in hatchlings and adults in the marine platyhelminth Macrostomum sp.: a bromodeoxyuridine analysis. Dev Biol. 2000;226(2):231-41.

12. Nimeth K, Ladurner P, Gschwentner R, Salvenmoser W, Rieger R. Cell renewal and apoptosis in Macrostomum sp. [Lignano]. Cell Biol Int. 2002;26(9):801-15.

13. Bode A, Salvenmoser W, Nimeth K, Mahlknecht M, Adamski Z, Rieger RM, et al. Immunogold-labeled S-phase neoblasts, total neoblast number, their distribution, and evidence for arrested neoblasts in Macrostomum lignano (Platyhelminthes, Rhabditophora). Cell Tissue Res. 2006;325(3):577-87

14. Verdoodt F, Bert W, Couvreur M, De Mulder K, Willems M. Proliferative response of the stem cell system during regeneration of the rostrum in Macrostomum lignano (Platyhelminthes). Cell Tissue Res. 2012;347(2):397-406.

15. Verdoodt F, Willems M, Mouton S, De Mulder K, Bert W, Houthoofd W, et al. Stem Cells propagate their DNA by random segregation in the flatworm Macrostomum lignano. PLoS ONE. 2012;7(1):e30227.

16. Grudniewska M, Mouton S, Simanov D, Beltman F, Grelling M, De Mulder $\mathrm{K}$, et al. Transcriptional signatures of somatic neoblasts and germline cells in Macrostomum lignano. Elife. 2016;5(DECEMBER2016):e20607.

17. Egger B, Ladurner P, Nimeth K, Gschwentner R, Rieger R. The regeneration capacity of the flatworm Macrostomum lignano-on repeated regeneration, rejuvenation, and the minimal size needed for regeneration. Dev Genes Evol. 2006;216(10):565-77.

18. Mouton S, Grudniewska M, Glazenburg L, Guryev V, Berezikov E. Resilience to aging in the regeneration-capable flatworm Macrostomum lignano. Aging Cell. 2018;17(3):e12739.

19. Mouton S, Willems M, Back P, Braeckman BP, Borgonie G. Demographic analysis reveals gradual senescence in the flatworm Macrostomum lignano. Front Zool. 2009;6:15.

20. De Mulder K, Kuales G, Pfister D, Egger B, Seppi T, Eichberger P, et al. Potential of Macrostomum lignano to recover from gamma-ray irradiation. Cell Tissue Res. 2010;339(3):527-42.

21. Egger B, Ishida S. Chromosome fission or duplication in Macrostomum lignano (Macrostomorpha, Plathelminthes) - Remarks on chromosome numbers in "archoophoran turbellarians". J Zool Syst Evol Res. 2005;43(2):127-32.

22. Zadesenets KS, Vizoso DB, Schlatter A, Konopatskaia ID, Berezikov E, Schärer $L$, et al. Evidence for karyotype polymorphism in the free-living flatworm, Macrostomum lignano, a model organism for evolutionary and developmental biology. PLoS ONE. 2016;11(10):e0164915.

23. Wasik K, Gurtowski J, Zhou X, Ramos OM, Delás MJ, Battistoni G, et al. Genome and transcriptome of the regeneration-competent flatworm. Macrostomum lignano. Proc Natl Acad Sci. 2015;112(40):12462-7.

24. Zadesenets K, Ershov N, Berezikov E, Rubtsov N. Chromosome evolution in the free-living flatworms: first evidence of intrachromosomal rearrangements in karyotype evolution of Macrostomum lignano (Platyhelminthes, Macrostomida). Genes. 2017;8(12):298.

25. Zadesenets KS, Schärer L, Rubtsov NB. New insights into the karyotype evolution of the free-living flatworm Macrostomum lignano (Platyhelminthes, Turbellaria). Sci Rep. 2017;7(1):6066.

26. Willems M, Egger B, Wolff C, Mouton S, Houthoofd W, Fonderie P, et al. Embryonic origins of hull cells in the flatworm Macrostomum lignano through cell lineage analysis: Developmental and phylogenetic implications. Dev Genes Evol. 2009;219(8):409-17.

27. Girstmair J, Telford MJ. Reinvestigating the early embryogenesis in the flatworm Maritigrella crozieri highlights the unique spiral cleavage program found in polyclad flatworms. Evodevo. 2019;10(1):12.

28. Janicke T, Marie-Orleach L, De Mulder K, Berezikov E, Ladurner P, Vizoso $\mathrm{DB}$, et al. Sex allocation adjustment to mating group size in a simultaneous hermaphrodite. Evolution. 2013;67(11):3233-42. 
29. Marie-Orleach L, Janicke T, Vizoso DB, Eichmann M, Schärer L. Fluorescent sperm in a transparent worm: validation of a GFP marker to study sexual selection. BMC Evol Biol. 2014;14(1):148.

30. Vizoso DB, Schärer L. Resource-dependent sex-allocation in a simultaneous hermaphrodite. J Evol Biol. 2007;20(3):1046-55.

31. Ramm SA, Lengerer B, Arbore R, Pjeta R, Wunderer J, Giannakara $A$, et al. Sex allocation plasticity on a transcriptome scale: socially sensitive gene expression in a simultaneous hermaphrodite. Mol Ecol. 2019:28(9):2321-41.

32. Schärer L, Littlewood DTJ, Waeschenbach A, Yoshida W, Vizoso DB. Mating behavior and the evolution of sperm design. Proc Natl Acad Sci. 2011;108(4):1490-5.

33. Lengerer $B$, Pjeta $R$, Wunderer J, Rodrigues $M$, Arbore $R$, Schärer $L$, et al. Biological adhesion of the flatworm Macrostomum lignano relies on a duo-gland system and is mediated by a cell type-specific intermediate filament protein. Front Zool. 2014;11(1):12.

34. Wunderer J, Lengerer B, Pjeta R, Bertemes P, Kremser L, Lindner $H$, et al. A mechanism for temporary bioadhesion. Proc Natl Acad Sci USA 2019;116(10):4297-306.

35. Egger B, Gschwentner R, Hess MW, Nimeth KT, Adamski Z, Willems M, et al. The caudal regeneration blastema is an accumulation of rapidly proliferating stem cells in the flatworm Macrostomum lignano. BMC Dev Biol. 2009;9:41.

36. Lengerer B, Wunderer J, Pjeta R, Carta G, Kao D, Aboobaker A, et al. Organ specific gene expression in the regenerating tail of Macrostomum lignano. Dev Biol. 2018;433(2):448-60.

37. De Mulder K, Pfister D, Kuales G, Egger B, Salvenmoser W, Willems M, et al. Stem cells are differentially regulated during development, regeneration and homeostasis in flatworms. Dev Biol. 2009;334(1):198-212.

38. Kuales G, De Mulder K, Glashauser J, Salvenmoser W, Takashima S, Hartenstein $\mathrm{V}$, et al. Boule-like genes regulate male and female gametogenesis in the flatworm Macrostomum lignano. Dev Biol. 2011;357(1):117-32.
39. Ladurner P, Pfister D, Seifarth C, Schärer L, Mahlknecht M, Salvenmoser W et al. Production and characterisation of cell- and tissue-specific monoclonal antibodies for the flatworm Macrostomum sp. Histochem Cell Biol. 2005;123(1):89-104.

40. Pfister D, De Mulder K, Philipp I, Kuales G, Hrouda M, Eichberger P, et al. The exceptional stem cell system of Macrostomum lignano: screening for gene expression and studying cell proliferation by hydroxyurea treatment and irradiation. Front Zool. 2007;4(1):9.

41. Pfister D, De Mulder K, Hartenstein V, Kuales G, Borgonie G, Marx F, et al. Flatworm stem cells and the germ line: developmental and evolutionary implications of macvasa expression in Macrostomum lignano. Dev Biol. 2008;319(1):146-59.

42. Marie-Orleach L, Janicke T, Vizoso DB, David P, Schärer L. Quantifying episodes of sexual selection: insights from a transparent worm with fluorescent sperm. Evolution. 2016;70(2):314-28.

43. Marie-Orleach L, Vogt-Burri N, Mouginot P, Schlatter A, Vizoso DB, Bailey NW, et al. Indirect genetic effects and sexual conflicts: partner genotype influences multiple morphological and behavioral reproductive traits in a flatworm. Evolution. 2017;71:1232-45.

44. Patlar B, Weber M, TemizyürekT, Ramm SA. Seminal fluid-mediated manipulation of post-mating behavior in a simultaneous hermaphrodite. Curr Biol. 2020;30(1):143-149.e4.

45. Grudniewska M, Mouton S, Grelling M, Wolters AHG, Kuipers J, Giepmans $\mathrm{BNG}$, et al. A novel flatworm-specific gene implicated in reproduction in Macrostomum lignano. Sci Rep. 2018;8(1):3192.

46. Egger B, Bachmann L, Fromm B. Atp8 is in the ground pattern of flatworm mitochondrial genomes. BMC Genomics. 2017;18(1):414.

\section{Publisher's Note}

Springer Nature remains neutral with regard to jurisdictional claims in published maps and institutional affiliations.
Ready to submit your research? Choose BMC and benefit from:

- fast, convenient online submission

- thorough peer review by experienced researchers in your field

- rapid publication on acceptance

- support for research data, including large and complex data types

- gold Open Access which fosters wider collaboration and increased citations

- maximum visibility for your research: over $100 \mathrm{M}$ website views per year

At BMC, research is always in progress.

Learn more biomedcentral.com/submissions 